\title{
DOUBLE-ALTERNATION LEARNING THROUGH TIME DISCRIMINATION AS A JOINT FUNCTION OF MOTIVATIONAL INSTRUGTIONS AND DISCRIMINANDA ${ }^{1}$
}

\author{
MICHIO BABA \\ Department of Educational Psychology, Ibaraki University
}

\begin{abstract}
The present study was concerned with the effects of the intensity of motivation and the difference between discriminanda (time to reinforcement) on double-alternation learning. 150 students were assigned to 5 motivation groups, each consisting of 3 discriminandum groups. Ss' task was to find out which of 2 response buttons was associated with a shorter (" correct") buzzer sound which changed its side in double-alternation. The 5 motivation groups differed significantly in mean $\log$ latency but not in number of correct responses. The increased difference in time to reinforcement for the positive and negative responses facilitated the choice performance but not the speed of response. These results were discussed in terms of the Yerkes-Dodson law, of which a variation of the Hullian explanation was proposed. An analysis of the present results revealed that the percentage of correct responses was a linear function of the difference between $\log$ correct and incorrect time to reinforcement.
\end{abstract}

A great number of experiments have been performed on the relationship between motivation and learning. Demonstrating that increased motivation does not always facilitate learning, these studies as a whole seem to confirm the YerkesDodson law originally established in animal studies. Particularly, Broadhurst (1959) and Hammes (1956) have reestablished the law. However, it seems to be difficult for most learning theories to explain the law in an integrated manner. For example, Hull-Spence's drive (1956), Bindra's arousal level (1959), and Tolman's cognitive map (1948) can easily explain the facilitating effect of motivation, for they assume that motivation is a facilitator itself. But they seem unable to

1 This report is based on $\mathrm{Ph}$. D thesis of the present author, submitted to Graduate School, Tokyo University of Education. He wishes to express his appreciation to Dr. N. Oka, Dr. S. Iwahara, and Dr. O. Fujita for their advices. provide a simple account for its interfering effect upon the learning. Spence (1956) proposed a derivation that drive reduces percentage of correct responses when the habit strength of a positive response is weaker than that of a negative one. Hebb (1955) suggested that high arousal interferes with delicate adjustments involved in cue function, by increasing irrelevant responses. Tolman (1948) simply stated that cognitive map becomes narrower under excessive motivation. According to Bruner, Matter, and Papanek (1955) high motivation narrows the breadth of learning. Bahrick, Fitts, and Rankin (1952) showed that increased incentive leads to a higher degree of selective attention. Saltz (1971) asserted that drive as stress breaks down the boundaries of S-R systems and permits the occurrence of competing responses. The present author using the white rat, demonstrated the negative effects of drive on choice performance, and proposed the drive-disinhibition hypothe- 
TABLE I

Experimental design and group designations: A $5 \times 3$ factorial design involving five levels of motivation and three levels of discriminanda

\begin{tabular}{|c|c|c|c|c|}
\hline \multirow{2}{*}{$\underset{\text { designation }}{\text { Group }}$} & \multirow{2}{*}{$\begin{array}{c}\text { Motivational instructions and } \\
\text { shock intensity }\end{array}$} & \multicolumn{3}{|c|}{ Longer buzzer $\uparrow$ durations (sec) } \\
\hline & & 2.6 & 3.2 & 4.4 \\
\hline $\mathrm{L}$ & $\begin{array}{l}\text { instructed as a test of apparatus and to } \\
\text { perform as slowly as they can. No shock. }\end{array}$ & $\mathrm{L}_{2.6}$ & $\mathrm{~L}_{8.2}$ & $\mathrm{~L}_{4.4}$ \\
\hline $\mathrm{M}$ & $\begin{array}{l}\text { instructed as a research of professor and to } \\
\text { perform at their pace. No shock. }\end{array}$ & $\mathrm{M}_{2.6}$ & $\mathrm{M}_{3.2}$ & $\mathbf{M}_{4.4}$ \\
\hline $\mathrm{H}$ & $\begin{array}{l}\text { instructed as concerned with intelligence } \\
\text { and to respond as quickly as they can. } \\
\text { No shock. }\end{array}$ & $\mathrm{H}_{2,6}$ & $\mathrm{H}_{3.2}$ & $\mathrm{H}_{4,4}$ \\
\hline$S$ & $\begin{array}{l}\text { same instructions as for Group M. Weak } \\
\text { shock. }\end{array}$ & $\mathrm{S}_{2.6}$ & $\mathrm{~S}_{3.2}$ & $\mathrm{~S}_{4.4}$ \\
\hline HS & $\begin{array}{l}\text { same instructions as for Group H. Strong } \\
\text { shock. }\end{array}$ & $\mathrm{HS}_{2,6}$ & $\mathrm{HS}_{3.2}$ & $\mathrm{HS}_{4.4}$ \\
\hline
\end{tabular}

$\uparrow$ Shorter buzzer duration was always $2.0 \mathrm{sec}$.

sis that drive releases negative response tendency (Baba, 1972). All these formulations imply that the competitive response is a critical factor determining the negative effect of motivation on performance.

In a previous study on human doublealternation learning, Baba (1973) found an interaction of motivation with difficulty of task. The experimental tasks involved were choice of one or the other finger key and alternating presses of two foot pedals, which were in competitive to each other. It was suggested that there were two distinct processes of learning, interfering with each other, and that the easier of the two might be facilitated by motivation and the more difficult inhibited. Similar results have been obtained in a number of studies: Castaneda (1956), Lee (1961), Glucksberg (1962), and Lipsitt and Lolordo (1963).

If the choice performance is impaired by the competitive response as in the above study, increased motivation or stress would be expected to facilitate the performance under condition of low or no response competition.

A hypothesis, that reduced reaction time by increased motivation leads to faster reinforcement and therefore improves choice performance, had been pro- posed by Reynolds $(1949,1950)$. According to the hypothesis, the intensity of motivation would not influence choice performance under the condition of low or no response competition, if the amount of time between the occurrence of response and its reinforcement (time to reinforcement) is held constant. In an unpublished study, Baba (1956) showed that variation in drive had no effect on learning in a T-maze by rats where the time to reinforcement was held constant. In the present study the competitive task was omitted from the framework of the previous study (Baba, 1973) and the time to reinforcement was held constant. Task difficulty was manipulated by varying the duration of the negative discriminanda. It was predicted that, under these conditions, motivation will not have any effects on choice performance. The experimental task of human subjects was to find the double-alternation rule through time discrimination.

\section{Method}

\section{Subjects}

The $S$ s were 150 undergraduates, 75 males and 75 females, recruited from Ibaraki University. They were randomly assigned to 15 
groups of $10 \mathrm{Ss}$ each, 5 males and 5 females.

\section{Experimental design}

A $5 \times 3$ factorial design was employed involving 5 levels of motivation and 3 levels of discriminandum durations (Table 1). Motivation was manipulated by different instructions and the discriminandum duration was controlled by means of an apparatus which sounded a buzzer, lighted signals, and delivered electric shocks. When the $S$ s depressed one of two button swithches to a signal, the buzzer was sounded. The duration of buzzer-sounding was contingent upon the button-press responses: One of the two buttons produced a shorter duration, the other a longer duration sometimes accompanied by shock. The position of the shorter-duration (" correct ") button was changed on every second trial. The $S \mathrm{~s}^{\text {" }}$ task was to determine the position of shorterduration button on each trial and depress it. Thus, they had to discriminate between longer and shorter stimulus durations and discover the double-alternation rule.

\section{Apparatus}

One of the apparatuses was a discrimination unit which consisted of a vertical board with two stimulus window, two button switches before the board, and a timer behind it. The other was a multiple-stimulation unit shielded by a drape which controlled the duration of buzzer sound, light, and their intervals. The two circular stimulus windows were $3 \mathrm{~cm}$ in diameter; one was located in the center of the board and delivered yellow light, and the other in the right of the center window delivering red light. The center yellow light signalled the $S \mathrm{~s}$ to start their response, and the right red light to stop it. The two button switches, separated $10 \mathrm{~cm}$ from each other, were located $60 \mathrm{~cm}$ under the right window and $60 \mathrm{~cm}$ before the vertical board.

The stimulation unit programmed the duration and sequence of the stimuli. The onset of the start signal automatically activated the electric timer, which the button-press response stopped. The experimenter read from the console of the timer whether a response was right or left, correct or incorrect, and the response latency.

\section{Procedure}

Ss were individually seated at the experimental table on which the apparatuses were set, given introductory instructions, and told to touch with their right middle-finger tip a mark which was $18 \mathrm{~cm}$ away from both of the buttons and on the edge of the table. For $S$ s in Groups S and HS, electrodes were fastened to their forefinger and fourth finger of the left hand by means of rubber bands.

The experimental steps were as follows :

Step 1 probed $S s^{\prime}$ position preference for five trials. The $S$ s were requested to depress either of the two buttons arbitrarily at the onset of the yellow light. The position of the button which an $S$ depressed three times or more for the five trials was defined as the preferred side.

Step 2. Motivational instructions, as shown in Table 1, were given. $S$ s in Groups $S$ and HS were told that the electric current was not going to be too severe and they should not unfasten the electrodes. For each $S$ of these two groups the threshold of electric shock was determined at steps of $5 \mathrm{~V}$ in an ascending order starting at $30 \mathrm{~V}$ AC. In the following experimental session, each $S$ of Groups $S$ and HS was shocked for $2 \mathrm{sec}$ at $5 \mathrm{~V}$ and $10 \mathrm{~V}$, respectively, higher than his threshold for his incorrect choice.

Step 3. The $S$ s received four pre-training trials of alternately depressing the two buttons : At first on the non-preferred side, second on the preferred side, and so on. The yellow starting signal and the red stopping signal were given at an interval of $6 \mathrm{sec}$ : Each one lasting for 1 sec. On the non-preferred-side response the buzzer was sounded for $2.0 \mathrm{sec}$ for all the groups. On the preferred side the buzzer duration was $2.6,3.2$, and $4.4 \mathrm{sec}$ depending upon the three discriminandum conditions. The electric shock was also introduced for $S$ s in Groups $\mathrm{H}$ and $\mathrm{HS}$ at this step. All the $S \mathrm{~s}$ were told to depress the button at the onset of the starting signal and not to detach it until the stopping signal came on.

Step 4 was for position learning for ten trials. 
The $S$ s were instructed to find out which of the two buttons resulted in shorter buzzer, and to consistently press the shorter-buzzer side, which was their non-preferred side.

Step 5. The double-alternation learning was started after the $S$ s were asked to depress the shorter-buzzer button consistently. On the first and second trials the correct side was the preferred side of each $S$, on the third and fourth trials his non-preferred side, and so on. The Ss were not given any information on response outcome except for the buzzer (and shock). Training was discontinued when an $S$ reached the criterion of 10 consecutive correct responses, or the 80 th trial.

At the end of the experiment, all the Ss were told that they should not discuss any aspects of the experiment with other. The main instructions were given through a tape-recorder.

\section{RESULTS}

In the position learning of Step 4, the three buzzer-duration conditions were significantly different in square-root transformed score of number of incorrect responses $(\sqrt{X+0.5}), F(4,70)=4.795, p<.05$. The effect of motivation and the interaction of motivation with discriminanda were not found in the score. Figure 1 shows the percentage of correct responses for the three buzzer durations, revealing that the largest difference in discriminanda improved best the choice performance in position learning. In the mean log latencies, the effect of motivation was significant, $F(4,120)=28.534, p<.005$, while any other effects were not. An inverse- $U$ relation between square root of number of incorrect responses and mean log latencies appears in Fig. 2. Assuming that the former is an index of learning and the latter of motivation, the relation between them may imply the Yerkes-Dodson law.

In the double-alternation learning, the effect of motivation on the choice performance was insignificant again. Table 2 shows the summary of an analysis of variance in the incorrect responses for the first 40 trials. The variances for the discriminanda and its interaction with trial block were significant. For the last 40 trials the five motivation groups $\mathrm{L}, \mathrm{M}, \mathrm{H}$, $\mathrm{S}$, and HS did not differ significantly in the number of $S$ s who attained 100 per cent correct, $\chi^{2}=5.555, d f=4, p>.2$. Figure 3 shows the performance of the three buzzerduration groups over 20 blocks of 4 trials, indicating that increased buzzer duration on the negative response leads to better performance. It is suggested that the difference in the buzzer durations for correct and incorrect responses was a critical variable in the double-alternation learning. While the increased differences between the correct- and incorrect-buzzer durations also increased the number of correct responses in the position learning, the effect was more pronounced in the double-alternation learning.

Mean log latencies of the button-pressing response for the first 12 trials of the

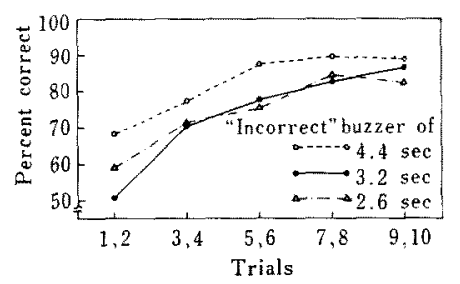

FIG. 1. Percentage of correct responses as a function of trials under different durations of the "incorrect" buzzer in position learning.

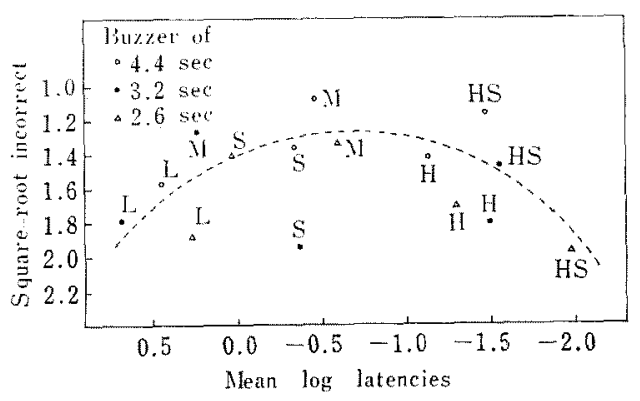

Fra. 2. The relation between response latency and number of incorrect responses in position learning. 
TABLE 2

Analysis of variance of incorrect response in double-alternation learning, using square-root transformed scores $(\sqrt{X+0.5})$

\begin{tabular}{|c|c|c|c|c|}
\hline & Source & $d f$ & $V$ & $F$ \\
\hline \multicolumn{5}{|c|}{ Between- $S$ s } \\
\hline $\mathrm{A}$ & Motivation & 4 & 2.0798 & 1.715 \\
\hline B & Discriminandum & 2 & 20.6295 & $17.013^{* * *}$ \\
\hline $\mathrm{C}$ & Sex & 1 & 1.0326 & \\
\hline & $\mathbf{A} \times \mathbf{B}$ & 8 & 0.4362 & \\
\hline & $A \times C$ & 4 & 0.3335 & \\
\hline & $\mathrm{B} \times \mathrm{C}$ & 2 & 0.0630 & \\
\hline & $\mathrm{A} \times \mathrm{B} \times \mathrm{C}$ & 8 & 1.2281 & \\
\hline $\mathrm{I}$ & Individual difference & 120 & 1.2126 & 1.013 \\
\hline \multicolumn{5}{|c|}{ Within-Ss } \\
\hline & Block of 20 trials & 1 & 59.4966 & $120.978 * * *$ \\
\hline & $\mathrm{D} \times \mathrm{A}$ & 4 & 0.2415 & \\
\hline & $\mathrm{D} \times \mathrm{B}$ & 2 & 3.7210 & $7.566 * * *$ \\
\hline & $\mathrm{D} \times \mathrm{C}$ & 1 & 0.4032 & \\
\hline & $\mathbf{D} \times \mathbf{A} \times \mathbf{B}$ & 8 & 0.1903 & \\
\hline & $\mathrm{D} \times \mathrm{A} \times \mathrm{C}$ & 4 & 0.2399 & \\
\hline & $\mathrm{D} \times \mathrm{B} \times \mathrm{C}$ & 2 & 0.1859 & \\
\hline & $\mathrm{D} \times \mathrm{A} \times \mathrm{B} \times \mathrm{C}$ & 8 & 0.5333 & 1.084 \\
\hline & $\mathrm{D} \times \mathrm{I}$ & 120 & 0.4918 & \\
\hline & Total & 299 & & \\
\hline
\end{tabular}

double-alternation learning are presented in Table 3 . The five motivation groups differed significantly in mean log latencies, $F(4,120)=30.533, p<.005$. The shortest latency of the five groups was for Group HS and the longest, for Group L. Table 4 represents differences in mean log laten-

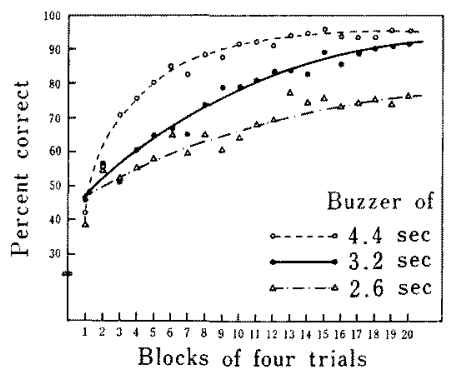

Fig. 3. Percentage of correct responses as a function of trials under different durations of the " incorrect"' buzzer in double-alternation learning. cies between paired groups. Both high motivation and strong electric shock shortened the latency of response significantly, while weak shock did not, as compared with the no-shock groups. Since the Motivation $\times$ Sex interaction was significant, $F(4,120)=4.452, p<.005$, analyses of variance were run for the male and female groups separately. The significant difference in the effect of motivation were found for the male, $F(4,70)=20.469, p<$ .001 , and for the female, $F(4,70)=13.809$, $p<.001$. Males in Group S showed shorter latency than males in Group $M$, but females in Group $S$ responded with longer latency than females in Group M. It might be that the males were more sensitive to the weak shock than the femalcs as Table 3 indicates.

In sum, while motivation and sex were 
TABLE 3

Mean $\log$ latencies for the first 12 trials of double-alternation learning

\begin{tabular}{c|c|c|c|c|c}
\hline Groups & Male (a) & Female (b) & $(\mathrm{a}+\mathrm{b}) / 2$ & $\mathrm{a}-\mathrm{b}$ & $t$ \\
\hline L & -0.022 & -0.078 & -0.050 & 0.056 & 0.158 \\
M & -0.187 & -1.129 & -0.658 & 0.942 & $2.661^{*}$ \\
H & -2.281 & -1.341 & -1.811 & -0.940 & $2.655^{*}$ \\
S & -1.036 & -0.323 & -0.679 & -0.713 & $2.014^{*}$ \\
HS & -2.409 & -2.517 & -2.463 & 0.108 & 0.305 \\
\hline Total & -1.187 & -1.077 & -1.132 & -0.110 & $d f=120$ \\
\hline
\end{tabular}

$* p<.05$

TABLE 4

Differences in mean $\log$ latencies for paired groups and associated $t$-values in double-alternation learning

\begin{tabular}{|c|c|c|c|c|c|c|}
\hline \multirow{2}{*}{$\begin{array}{l}\text { Paired } \\
\text { groups }\end{array}$} & \multicolumn{2}{|c|}{ Total } & \multicolumn{2}{|c|}{ Males } & \multicolumn{2}{|c|}{ Females } \\
\hline & Dif. & $t$ & Dif. & $t$ & Dif. & $t$ \\
\hline$M-L$ & -0.608 & $2.422 *$ & -0.165 & 0.466 & -1.051 & $2.960 * *$ \\
\hline $\mathrm{H}-\mathrm{L}$ & -1.761 & $7.016 * * *$ & -2.259 & $6.381^{* * *}$ & -1.263 & $3.568 * * *$ \\
\hline $\mathrm{H}-\mathrm{M}$ & -1.153 & $4.594 * * *$ & -2.094 & $5.915^{* * *}$ & -0.212 & 0.599 \\
\hline $\mathrm{S}-\mathrm{M}$ & -0.021 & 0.084 & -0.849 & $2.398 *$ & 0.806 & $2.277^{*}$ \\
\hline HS-H & -0.652 & $2.598^{*}$ & -0.128 & 0.362 & -1.176 & $3.322 * *$ \\
\hline$d f=120$ & $p<.05$ & $* * p<.01$ & $<.001$ & & & \\
\hline
\end{tabular}

critical determinants of response latency, the difference in correct and incorrect buzzer durations was not. In the correct response, on the contrary, the buzzer duration was a crucial factor of learning, but motivation and sex were not. Considering these findings together, the old notion seems to be confirmed that motivation is a critical factor of performance but not of learning.

\section{Discussion}

The results substantiated the hypothesis that motivation does not have any effect on the learning under the condition of low response competition when the time to reinforcement is held constant. At the same time, Spence's hypothesis, that motivation interferes with learning under the condition of high response competition, would seem to be indirectly confirmed.
For the author's previous study showed the interference effect of motivation under the condition of high response competition (Baba, 1973), and the present study revealed no interference effect of motivation under the condition of low response competition.

However, the present study does not positively confirm Spence's hypothesis, because the present learning process might have involved a number of competitive responses (e.g., the incorrect response of long-buzzer pressing, the position preference, and $\mathrm{Ss}_{\mathrm{s}}$ other hypothesis-making responses). Particularly, for the first two trials of double-alternation learning the incorrect, long-buzzer side was the correct side of the preceding position learning. Therefore, the incorrect response tendency should be expected to be stronger than that of the correct, thus leading one to predict that increased motivation would reduce 
choice performance. Actually, data during the first half of the learning did not support the prediction.

A somewhat inverse-U-shaped relation between mean square root of number of correct responses and log latency is shown in Fig. 4 as in Fig. 2. The relation suggests the Yerkes-Dodson law again. If such was the case, Spence's hypothesis would have to be discarded or modified. Although some of the other hypotheses, such as Hebb's, Tolman's and Easterbrook's, are advantageous in explaining the inverse- $U$ curve, they do not specify the conditions or the factors which determine the curve and do not organize the whole facts of the Motivation $\times$ Learning interaction. The present author proposes a systematic explanation of the interaction by modifying Spence's hypothesis.

As the first step of the modification Hull's equation, ${ }_{s} E_{r}={ }_{s} H_{r} \times D$, is revised according to Iwahara (1957) and Jones (1960) as follows:

$$
E=\left(H-{ }_{s} I_{r}\right)\left(D-I_{r}\right)
$$

where $E$ refers to excitatory potential, $H$ habit strength, ${ }_{s} I_{r}$ conditioned inhibition, $D$ drive, and $I_{r}$ reactive inhibition.

At the second step, according to Spence's theoretical formulation of differential instrumental conditioning, the excitatory potentials $(E)$ of the positive and negative

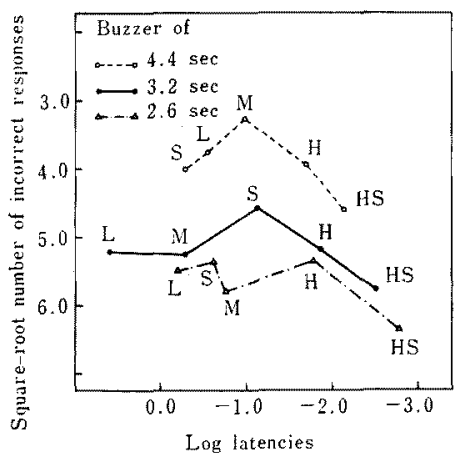

FIG. 4. The relation between response latency and number of incorrect responses in doublealternation learning. responses are given by the following equations:

$$
\begin{aligned}
& E_{+}=H_{+} \times D \\
& \left.E_{-}=\left[H_{-}-{ }_{s} I_{r}-d\right)\right] \times D
\end{aligned}
$$

where $H_{+}$denotes positive habit strength, $H_{-}$negative habit strength, and $d$ drivedisinhibition of conditioned inhibition $\left({ }_{s} I_{r}\right)$.

Assuming that percentage of correct responses is a function of the difference between $E_{+}$and $E_{-}$, equation (2) and (3) lead to the third step:

$$
E_{+}-E_{-}=D \times\left[H_{+}-H_{-}+\left({ }_{s} I_{r}-d\right)\right] .
$$

Abbreviating $H_{+}-H_{-}{ }_{s} I_{r}$ by $h$ and substituting $i D$ for $d$, the equation becomes as follows:

$$
E_{+}-E_{-}=D(h-i D) .
$$

Curves of the equation are given in Fig. 5 for the case of $i=0.4$, and $h=1.0,0.4$, and 0.0 , where the abscissa represents drive strength. Since the percentage of correct responses would be a function of the difference $E_{+}-E_{-}$it appears that the curves fairly well represent the Yerkes-Dodson law. Compared with Spence's formulation the equation can better predict the interference effect of drive on performance if $h$ is not negative. Especially, it predicts an inversed-U curve with $h=0.4$.

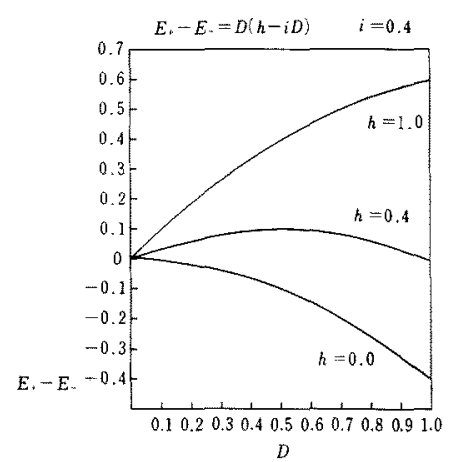

Fig. 5. Theoretical curves of net excitatory potentials as a joint function of drive $(D)$ and discriminanda $(h)$. 
Thus, the whole body of data on the Learning $\times$ Motivation interaction may be explained in an integrated manner and organized by the theoretical framework of the Hull-Spence tradition. Although the present results can not statistically confirm the Yerkes-Dodson law, the curves illustrated in Fig. 4 are similar to the theoretical curves in Fig. 5.

Recently Kahneman (1973) proposed an explanation of the Yerkes-Dodson law using the Easterbrook hypothesis. In short, he suggested that a state of high arousal was associated with such effects as narrowed attention, increased lability of attention, difficulties in controlling attention by discrimination, and systematic changes of strategy in various task. The present hypothesis would explain these attentional effects of arousal by proposing a Hullian deduction. In equation (5) the term $h$ implies difficulties in discrimination, and $-i D$ denotes the increased lability of attention by drive in competitive tasks.

So far the motivational effects on the performance have been discussed. With respect to the other experimental conditions, the buzzer durations as discriminanda (time to reinforcement), the experimental results clearly indicated that the greater differences in time to reinforcement between positive and negative responses yields better performance (Fig. 3). The present author asserts that the motiva-

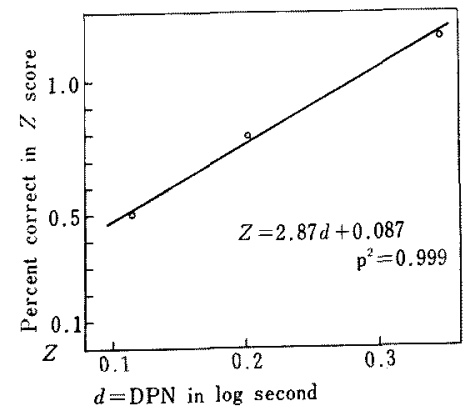

FIG. 6. The relation of DPN to percentage of correct responses. tional effect on choice performance depends upon the difference between positive and negative reaction times (DPN), and that the difference is a determinant of percentage of correct responses (Baba, 1972). Since the present experiment held time to reinforcement constant, the time difference should have a clearer relation to the percentage of correct responses. Figure 6 showed the relation in the present double-alternation learning, where the percentage of correct responses for all the trials of the double-alternation learning was transformed into the $Z$ score while DPN denotes the difference between positive and negative log buzzer durations. The fact that a line fitted by the method of least squares approximates the plotted data fairly well suggests that DPN is a factor in determining the percentage of correct responses.

\section{REFERENCES}

BABA, M. 1956 Motivation and learning. Unpublished master thesis, Tokyo University of Education.

BABA, M. 1972 Percentage of correct responses and running time as a function of drive. Japanese Journal of Psychology, 43, 76-85 (In Japanese with English Abstract).

BABA, M. 1973 Double alternation learning and reaction time as a function of motivational instruction. Japanese Journal of Psychology, 44, 68-78 (In Japanese with English Summary).

BAHRICK, H.P. 1954 Incidental learning under two incentive conditions. Fournal of Experimental Psychology, 47, 170-172.

Bahrick, H. P., Fitts, P. M., \& Rankin, R. E. 1952 Effect of incentives upon reactions to peripheral stimuli. Fournal of Experimental Psychology, 44, 400-406.

Bindra, D. 1959 Motivation: A systematic reinterpretation. New York: Ronald.

Broadhurst, P. L. 1959 The interaction of task difficulty and motivation: The YerkesDodson law revived. Acta Psychologica, 16, 321-338.

Bruner, J.S., Matter, J., \& Papanek, M.L. 1955 Breadth of learning as a function of drive level and mechanization. Psychological 
Review, 62, 1-10.

Castaneda, A. 1956 Effects of stress on complex learning and performance. Journal of Experimental Psychology, 52, 9-12.

EAsterbrook, J.A. 1959 The effect of emotion on cue utilization and the organization of behavior. Psychological Review, 66, 189-201.

GLucksBerg, S. 1962 The influence of strength of drive on functional fixedness and perceptual recognition. Journal of Experimental Psychology, 63, 36-41.

Hammes, H. A. 1956 Visual discrimination learning as a function of shock-fear and task diffculty. Foumal of Comparative and Physiological Psychology, 49, 481-484.

HeвB, D. O. 1949 The Organization of Behaviour. London: Wiley.

Hers, D. O. 1955 Drives and the C. N.S. Psychological Review, 62, 243-254.

IWAHARA, S. 1957 Hull's concept of inhibition: A revision. Psychological Reports, 3, 9-10.

JoNes, H. G. 1960 Learning and abnormal behaviour. In H.J. Eysenck, (Ed.), Handbook of abnormal psychology. London: Pitman.

Kahneman, D. 1973 Attention and effort. N.J.: Prentice-Hall.

LEE, L. C. 1961 The effects of anxiety level and shock on a paired-associate verbal task. Journal of Experimental Psychology, 61, 213-217.
LipsitT, L. P., \& Lolordo, V. M. 1963 Interaction effect of stress and stimulus generalization on children's oddity learning. Journal of Experimental Psychology, 66, 210-214.

Reynolds, B. 1949 The relationship between the strength of a habit and the degree of drive present during acquisition. Journal of Experimental Psychology, 39, 296-306.

REYNoLDs, B. 1950 Acquisition of a simple spatial discrimination as a function of the amount of reinforcement. Fournal of Experimental Psychology, 40, 152-162.

SAltz, E. 1971 The cognitive bases of human learning. III.: Dorsey.

SPENCE, K. W. 1956 Behavior theory and conditioning. Conn.: Yale Univ.

Spence, K. W. 1958 Behavior theory and selective learning. In M.R. Jones, (Ed.), Nebraska Symposium on Motivation 1958. Nebr.: Univ. of Nebraska.

Spence, K.W., Goodrich, K. P., \& Ross, L. E. 1959 Performance in differential conditioning and discrimination learning as a function of hunger and relative response frequency. Fournal of Experimental Psychology, 58, 8-16.

Tolman, E. C. 1948 Cognitive maps in rats and men. Psychological Review, 55, 189-208.

(Received Feb. 18, 1976) 